\title{
A Content Analysis of Health Promotion Topics Selected by an Old Order Mennonite Community
}

\author{
M. Eve Main, DNP, APRN-BC \\ Professor \\ Western Kentucky University School of Nursing and Allied Health \\ Dawn Garrett-Wright, PhD, PMHNP-BC, CNE \\ Professor \\ Western Kentucky University School of Nursing and Allied Health \\ M. Susan Jones, PhD, RN, CNE, ANEF \\ Professor Emerita \\ Western Kentucky University School of Nursing and Allied Health \\ Corresponding Author \\ M. Eve Main \\ eve.main@wku.edu \\ WKU SONAH \\ 1906 College Heights Blvd \\ Bowling Green, KY 42101 \\ 270-745-3489
}

\begin{abstract}
In the United States, population growth in the Anabaptists has increased in the past 60 years, and Kentucky is one of the few southern states with a significant Plain Anabaptist population. One Old Order Mennonite community in south central Kentucky has hosted monthly health promotion days for over 18 years in partnership with a university. Using a community-based participatory model, community members identify the health promotion topic (HPT) of interest each month and the academic partners seek an appropriate speaker to lead a discussion on the selected topic. Using a qualitative design with content analysis, four researchers examined each HPT for frequency and categorization. The health promotion topic categories included communicable disease, health lifestyle practices, mental health conditions, navigating the health care system, self-care for illness or injury, and quest for medical knowledge.
\end{abstract}

Submitted February 3, 2020; accepted June 15, 2020; published September 18, 2020

https://doi.org/10.18061/jpac.v1i1.7548

Keywords: Old Order Mennonite, health promotion, education, community-based participatory research

$\mathrm{I}^{\mathrm{n}}$

$\mathrm{n}$ the United States, population growth in Anabaptists has increased in the past 60 years, with the population doubling every 20 to 25 years (Donnermeyer \& Cooksey, 2010). A school of nursing, an area health education center, and one Old Order Mennonite (OOM) community have partnered to cohost monthly health promotion days for more than 18 years. Using a qualitative 
research design with content analysis, four researchers examined each health promotion topic (HPT) selected by members of the OOM community for frequency and categorization of the topic. The aim of this paper is to quantify and categorize HPTs chosen by an OOM community over nearly two decades. Examining types and frequency of topics the OOM community requested to be discussed on health promotion days provides greater understanding of the health views and concerns of one OOM community.

\section{Background}

The increase in the Anabaptist population has influenced the spread of the Amish and Mennonites from the more populous states of Pennsylvania and Ohio. Within the Anabaptist population, there is diversity related to the ownership of motorized vehicles and the adoption of other technology. Kentucky is one of the few southern states with a significant Plain Anabaptist population (Donnermeyer \& Anderson, 2014). Old Order Amish settlements are in 45 Kentucky counties with an estimated population of 13,595. The Old Order Mennonite estimated population for Kentucky is 1,187 (Young Center for Anabaptist and Pietist Studies, 2020). Further evidence of the growth in Kentucky is a genetic medical clinic, founded in 2018, to increase access for Anabaptists to genetic testing and diagnosis of rare conditions (Hunt et al., 2019).

The OOMs in this analysis, described as "Wengers" or "horse-and-buggy Mennonites," originated in 1927 following a split from progressive Mennonites over the use of automobiles (Kraybill \& Hurd, 2006). Other areas of disagreement centered on faith-based issues such as the primary use of the English language in church services. Most "horse-and-buggy Mennonites" speak Pennsylvania German in the home and conduct church services in a mixture of Pennsylvania German and High German. Children attend school through the eighth grade, which is taught in English (Scott, 1996). The use of horse-drawn implements with steel wheels is a sign of their continued opposition to car ownership; however, the OOM groups do use motorized transportation. OOMs accept or reject modernization selectively, rejecting it if the modernization is perceived as a threat to their way of life (Kraybill \& Hurd, 2006). After 1950 many of these OOMs migrated from Lancaster County, Pennsylvania, to other states in search of farmland and rural settings, allowing them a path in maintaining their traditional life.

The targeted population for this study was an OOM community founded in 1978, originating from central Pennsylvania, and located in south central Kentucky with an estimated population of between 800 and 1,000 congregants. The community has been described as technologically primitive with two districts and affiliated settlements in Tennessee, Missouri, Belize, and Ohio (Donnermeyer \& Anderson, 2014). The majority of the OOMs continue to farm, but also practice woodworking, roofing, and home construction, and operate food markets. However, the targeted OOM community is the most conservative of the OOMs and are respectfully referred to as Plain People. Horse-drawn implements rather than tractors are used and members' multiple construction skills are not typically shared outside the local OOM community. Their connection to the land is 
the main occupational focus, which allows members of the OOM community to produce agricultural products for their families and the local markets while remaining embedded in their culture.

The relationship of the OOM community and a nursing faculty member from a regional university has spanned 25 years. The first encounters, covering approximately six years, began when the nursing faculty member worked with a contact person in the OOM community to facilitate completion of academic projects in community health nursing courses by individuals and small groups of students. Examples of these projects included creating a poster on buggy safety, completing an honor's thesis on maple syrup urine disease, and creating a brochure on the multifaceted faces of cancer. The establishment of this relationship required time as mutual trust and respect was built between the academic partner and members of the OOM community (Jones et al., 2013).

Over time, the academic partners expanded and Health Promotion Day or "Clinic Day," as it is known in the OOM community, was established. Clinic Day has been held on the second Tuesday of each month for over 18 years (Jones et al., 2013). The primary goal of the OOM partnership is to provide future physicians, nurses, and other health science students with a crosscultural educational experience while providing basic health screening, education, and primary care for members of an OOM community. OOM community members are asked to select the focus of the HPTs. In the month prior to the meeting, a small group of OOMs talks with other community members and reviews current health issues to choose a topic. Specific questions related to the chosen topic are also requested as well as any areas of the topic that may be culturally sensitive. The chosen HPT is communicated to the academic partners, and a collaborative approach allows the project team to identify the most appropriate person to lead the discussion. Experts or experienced individuals on the selected topic are considered along with the speaker's ability to deliver the message in a culturally sensitive manner. Orientation of the presenter includes information on Anabaptist history, low-technology community norms, and the types of educational materials appropriate for viewing in the community or sharing among community members. The presenters are told they should be prepared for basic and advanced questions. During or following each HPT, the presenter asks for OOM health care practices and experience in relation to the HPT. The one-hour educational program is followed by a primary care clinic staffed by family medicine residents, nurse practitioners, and nursing students offering health screening for blood pressure, lipid, and glucose testing.

The academic partners and other volunteers are acutely aware of the "outsider" role of the academic institution. The HPTs as well as the other Clinic Day activities are delivered within the framework of the community-based participatory research (CBPR) model (Israel et al., 2001). CBPR offers guidelines for adopting an approach for community engagement that is inclusive, collaborative, and equitable, with the aim of combining knowledge and activities to improve health. These principles are displayed in Table 1 with the associated OOM project activities. 
Table 1

CBPR Principles and Activities

\begin{tabular}{|c|c|}
\hline CBPR Principle & OOM Activity \\
\hline \multirow[t]{4}{*}{$\begin{array}{l}\text { Recognizes community as a unit of } \\
\text { identity }\end{array}$} & $\begin{array}{l}\text { Postcards are mailed to all households announcing HPT, } \\
\text { date, location }\end{array}$ \\
\hline & Announcements are posted in church \\
\hline & $\begin{array}{l}\text { The educational presentations utilize low technology (paper } \\
\text { handouts, no photographs, no electronic equipment) }\end{array}$ \\
\hline & $\begin{array}{l}\text { Speaker orientation to the OOM community is completed } \\
\text { by project staff }\end{array}$ \\
\hline \multirow[t]{5}{*}{$\begin{array}{l}\text { Builds on strengths and resources within } \\
\text { the community }\end{array}$} & $\begin{array}{l}\text { Insider contacted } 1 \text { to } 2 \text { months prior to the presentation to } \\
\text { find suggestions for HPT }\end{array}$ \\
\hline & Clinic is held in an OOM home \\
\hline & $\begin{array}{l}\text { Solicitation of names from the community on known topic } \\
\text { experts }\end{array}$ \\
\hline & Discussion of potential speakers within the project staff \\
\hline & $\begin{array}{l}\text { Overt attempts are made to ask about the knowledge and } \\
\text { experience with the topic in the community }\end{array}$ \\
\hline \multirow[t]{3}{*}{$\begin{array}{l}\text { Integrates knowledge and action for } \\
\text { mutual benefit of all partners }\end{array}$} & $\begin{array}{l}\text { HPT identified by the community, explored by the academic } \\
\text { partners related to specific community } \\
\text { concerns/questions }\end{array}$ \\
\hline & Speaker chosen that demonstrates cultural sensitivity \\
\hline & $\begin{array}{l}\text { Consultation with the community on HPT content and the } \\
\text { possibility of conflict with the community values and } \\
\text { norms }\end{array}$ \\
\hline \multirow[t]{3}{*}{$\begin{array}{l}\text { Addresses health from both positive and } \\
\text { ecological perspectives }\end{array}$} & $\begin{array}{l}\text { HPTs are incorporated with other screenings for blood } \\
\text { pressure, high cholesterol, and high triglycerides }\end{array}$ \\
\hline & $\begin{array}{l}\text { Environmental and behavioral issues of the OOM } \\
\text { community are considered when exploring potential } \\
\text { HPTs }\end{array}$ \\
\hline & $\begin{array}{l}\text { Incorporation of research on alternative/complementary } \\
\text { care for most topics if appropriate }\end{array}$ \\
\hline \multirow[t]{2}{*}{$\begin{array}{l}\text { Disseminates findings and knowledge } \\
\text { gained to all partners }\end{array}$} & $\begin{array}{l}\text { Research disseminated to the community prior to } \\
\text { publication }\end{array}$ \\
\hline & $\begin{array}{l}\text { Extra handouts are provided for community members that } \\
\text { could not attend the HPT offering }\end{array}$ \\
\hline \multirow[t]{4}{*}{$\begin{array}{l}\text { Involves a long-term commitment by all } \\
\text { partners }\end{array}$} & $\begin{array}{l}\text { Participation by community and academic partners for } 18 \\
\text { years }\end{array}$ \\
\hline & 2nd Tuesday is the set scheduled date \\
\hline & Informal surveying of "are we meeting each other's needs" \\
\hline & $\begin{array}{l}\text { All efforts are made to maintain the monthly schedule } \\
\text { including alternate communication methods if cancelled }\end{array}$ \\
\hline
\end{tabular}


The OOMs prefer face-to-face socialization, so prior to each monthly clinic, an academic partner visits the community to confirm the monthly topic. When Clinic Day is cancelled due to inclement weather, a backup system has been developed to facilitate the notification of the community. The OOMs know that if the county school system is not in session (i.e., the buses do not run), Clinic Day is cancelled. On some occasions the community has asked for suggestions from the project staff for HPTs. Some topics suggested by the project staff related to a need observed in the community have been rejected by the community. The wishes of the community related to the topic to be presented are always respected.

\section{Aims and Methods}

A qualitative design using a content analysis approach was used to analyze the HPTs chosen by an OOM community over an 18-year span. Content analysis is a systematic and objective process for quantifying and describing phenomena. The researchers followed the process of content analysis as recommended by Elo \& Kyngäs (2008). This study was approved by the university's institutional review board. The aim of this paper is to quantify and categorize HPTs chosen by the OOM community over nearly two decades.

The researchers, including three nurses and one public health administrator, have been involved with the community on an ongoing basis, participating through health promotion activities, finding appropriate HPT speakers, and functioning as community resources. One researcher recorded the HPTs by month and year beginning in 2002. The initial set of categories was chosen based on the four researchers' experience in the community. These categories included communication, medical conditions, infectious disease, environmental hazards, prevention, and self-care, and each researcher reviewed the HPTs for placement in the initial six categories.

In the first categorization, the HPTs were listed chronologically on a template with the corresponding choice of initial categories. Each researcher categorized the HPTs separately, without knowledge of other researchers' ratings. Following the first categorization of HPTs, the selections by each rater were reviewed by all researchers and the categories were refined to communicable disease, healthy lifestyle practices, mental health conditions, navigating the health care system, and self-care for illness or injury. The HPTs were reviewed and categorized on a template for a second categorization. The researchers discussed the coherence of the five categories and the HPTs that they were unable to categorize, and a sixth category, titled "quest for medical knowledge," was added. The quest-for-medical-knowledge category was created to address HPTs chosen by the community for which there was no apparent increased risk in the community and/or no community member was known to have the identified condition/health issue. The categorization of HPTs was repeated for a final time. The immersion in the data (HPTs) by the raters was lengthy and occurred over three months.

Statistical analysis was completed by a university statistician. The Fleiss' kappa is the recommended statistical test to examine rater reliability with more than two raters and more than two categories (Fleiss, 1971; Perinetti, 2017) and was conducted to examine the agreement 
between four unique raters on the categorization of 127 HPTs. The kappa statistic is an extension of the Cohen's kappa and used to measure nominal scale agreement among more than two raters (Perinetti, 2017). Kappa values range from 0 to 1 , with " 0 " indicating poor agreement and " 1 " indicating perfect agreement. All ratings were completed separately by each of the four raters. The Landis scale has been commonly used for the interpretation of the kappa statistic and includes the following interpretations: 0 or less indicating chance agreement, .01-.20 indicating slight agreement, .21-.40 indicating fair agreement, .41-.60 indicating moderate agreement, .61-.80 indicating substantial agreement, and .81-.99 indicating almost perfect agreement (Landis, 1996; Viera \& Garrett, 2005). The data analysis was generated using SAS software, Version 9.4.

\section{Results}

From 2002 through 2018, 127 HPTs were presented in the OOM community. The annual frequency of HPTs increased from 7 in 2002 to 13 in 2018 with an overall average of 7.1 HPTs. The average number of HPTs has increased since 2011 with an average of 10.8 HPTs each year. HPT speakers included persons in a wide variety of professions and occupational preparation including audiologists, biologists, licensed clinical social workers, coroners, dieticians, environmentalists, health educators, health system administrators, medical students and residents, nurses, nurse practitioners, paramedics, pharmacists, physicians, optometrists, physical therapists, educators, and elected local and state officials.

Examples of topics from each category are displayed in Table 2. Eight percent (10/127) of all HPTs during this time frame were categorized as communicable disease-related (see Table 3 for yearly HPTs). Fourteen percent (18/127) of all HPTs were categorized as healthy lifestyle practices. HPTs categorized as mental health conditions were identified in 7\% (9/127) of all HPTs. HPTs categorized as navigating the health care system were identified in 8\% (10/127) of all HPTs. HPTs categorized as self-care for illness or injury represented $28 \%(36 / 127)$ of all HPTs. Finally, the quest for medical knowledge category was represented by 35\% (44/127) of all HPTs. 
Table 2

Categories and Examples of HPTs

\begin{tabular}{|c|c|}
\hline Category & Examples of HPTs \\
\hline Communicable Disease & $\begin{array}{l}\text { toxoplasmosis; meningitis; West Nile virus; genital herpes; antibiotic } \\
\text { soap; antibiotic resistance and hand washing; streptococcus and } \\
\text { staphylococcus }\end{array}$ \\
\hline Healthy Lifestyle Practices & $\begin{array}{l}\text { vitamins and minerals; healthy cholesterol ranges; lifting techniques and } \\
\text { sleeping posture to prevent pain and injury; breast self-examination; } \\
\text { nutrition for teenage girls and pregnant women; childhood obesity; } \\
\text { colon cancer: causes, prevention, symptoms, diagnosis, and treatment }\end{array}$ \\
\hline Mental Health Conditions & $\begin{array}{l}\text { effects of anxiety on the body; postpartum depression; strategies to } \\
\text { maintain mental sharpness; depression; stress management; } \\
\text { managing emotional crisis/compulsive disorders; anger and } \\
\text { depression; Alzheimer's disease and dementia. }\end{array}$ \\
\hline $\begin{array}{l}\text { Navigating the Health Care } \\
\text { System }\end{array}$ & $\begin{array}{l}\text { how to agreeably disagree with your doctor; elder care; hospice and } \\
\text { preserving quality of life; emergency medical services; advanced } \\
\text { directives and living wills; the Patient Protection and Affordable Care } \\
\text { Act; introduction to the WeCare Clinic }\end{array}$ \\
\hline $\begin{array}{l}\text { Self-care for Illness or } \\
\text { Injury }\end{array}$ & $\begin{array}{l}\text { summer skin disorders; dandruff; burn treatment class; pain medication; } \\
\text { non-pharmacological pain managements; learning to use the ear } \\
\text { scope; common ear problems; lung sounds/learning to use the } \\
\text { stethoscope; identifying my cough; suturing; recognizing different types } \\
\text { of shock; choking prevention; CPR; heart arrhythmias; blood clots, } \\
\text { phlebitis, varicose veins; caring for musculoskeletal injuries; common } \\
\text { foot problems; muscle pain; chronic back pain; analyzing abdominal } \\
\text { pain; urinary infections }\end{array}$ \\
\hline $\begin{array}{l}\text { Quest for Medical } \\
\text { Knowledge }\end{array}$ & $\begin{array}{l}\text { hormones and their actions; role of the immune system; adrenal gland } \\
\text { function; common problems of the liver; hypoglycemia and } \\
\text { hyperglycemia; herbal supplements; relationship of diabetes and heart } \\
\text { disease; Lynch syndrome; pancreatic disease; toxemia of pregnancy; } \\
\text { multiple sclerosis; celiac disease; hearing loss; anorexia; well child } \\
\text { assessment; what's going on when we get older; health problems of } \\
\text { OOM communities }\end{array}$ \\
\hline
\end{tabular}

A confidence interval (CI) is identified in the following results and indicates a $95 \%$ certainty that a true mean of the population is found in the CI. The Fleiss' kappa for overall agreement demonstrated substantial agreement between the four raters, $\kappa=.802$ (95\% CI [.801, .803]), $p<$ .0005. The Fleiss' kappas for agreement within the final six categories were .966 (CI [.963, .968]) for communicable disease, .721 (CI $[.719, .723]$ ) for healthy lifestyle practices, .872 (CI [.870, $.874]$ ) for mental health conditions, 1.00 (CI [.998, 1.002]) for navigating the health care system, .868 (CI [.866, .870) for self-care for illness or injury, and .711 (quest for medical knowledge). All category Fleiss' kappa statistics had a significance level of .0005. 
Table 3

HPT Frequency and Percentage by Year and Category

\begin{tabular}{|c|c|c|c|c|c|c|}
\hline Year & $\begin{array}{c}C D \\
n(\%)\end{array}$ & $\begin{array}{l}\text { HLP } \\
n(\%)\end{array}$ & $\begin{array}{l}\mathrm{MHC} \\
n(\%)\end{array}$ & $\begin{array}{c}\mathrm{NHCS} \\
n(\%)\end{array}$ & $\begin{array}{c}\text { SC } \\
n(\%)\end{array}$ & $\begin{array}{c}\text { Quest } \\
n(\%)\end{array}$ \\
\hline 2002 & & $1(14)$ & $1(14)$ & & $3(43)$ & $2(29)$ \\
\hline 2003 & & & & & & $3(100)$ \\
\hline 2004 & $1(25)$ & $1(25)$ & $1(25)$ & & $1(25)$ & \\
\hline 2005 & & $1(100)$ & & & & \\
\hline 2006 & & $1(20)$ & $2(40)$ & & & $2(40)$ \\
\hline 2007 & & & & $1(33)$ & $2(67)$ & \\
\hline 2008 & & $1(33)$ & & & & $2(67)$ \\
\hline 2009 & & $3(38)$ & & $1(13)$ & & $4(50)$ \\
\hline 2010 & & & & & $2(29)$ & $5(71)$ \\
\hline 2011 & & & & & $1(25)$ & $3(75)$ \\
\hline 2012 & $1(9)$ & $1(9)$ & $3(27)$ & & $2(18)$ & $4(36)$ \\
\hline 2013 & $1(8)$ & $1(8)$ & $1(8)$ & $4(33)$ & $2(17)$ & $3(25)$ \\
\hline 2014 & $2(18)$ & $2(18)$ & & & $5(45)$ & $2(18)$ \\
\hline 2015 & $2(17)$ & $1(8)$ & & & $6(50)$ & $3(25)$ \\
\hline 2016 & & $1(9)$ & & $3(27)$ & $4(36)$ & $3(27)$ \\
\hline 2017 & $1(8)$ & $1(8)$ & $1(8)$ & & $5(42)$ & $4(33)$ \\
\hline 2018 & $2(15)$ & $3(23)$ & & $1(8)$ & $3(23)$ & $4(31)$ \\
\hline
\end{tabular}

$\mathrm{CD}=$ Communicable Disease; HLP = Healthy Lifestyle Practices; $\mathrm{MHC}=$ Mental Health Conditions; NHCS = Navigating the Health Care System; SC = Self-Care for Illness or Injury; Quest = Quest for Medical Knowledge

\section{Discussion}

The purpose of this study was to quantify and categorize the HPTs chosen in one OOM community over 18 years. The HPT categories identified were communicable disease, healthy lifestyle practices, mental health conditions, navigating the health care system, self-care for illness or injury, and quest for medical knowledge. Topics categorized as quest for medical knowledge were the most frequently chosen HPTs and were chosen by participants more than one-third of the time. In this OOM community, formal education through the 8th grade is a common practice, and if science is taught in the schools, the use of outdated textbooks may occur (Gillum et al., 2011). However, while basic education maybe limited, reading printed sources (magazines, journals, and letters) and writing letters is common in the OOM community. This observation contrasts with other studies. Limited health literacy was identified among the Ohio Amish, with approximately $12 \%$ of Amish participants reading at or lower than a 6 th grade level as compared to $2.6 \%$ of the non-Amish participants (Katz et al., 2013). The questions posed prior to and during the Clinic Day related to the HPTs are 
thoughtful and informed by the OOMs' reading on health issues. In addition, their quest for medical knowledge has continued outside the monthly clinic. Special classes and projects have been addressed based on specific requests of members of the OOM community, including discussions by experts on recognizing mental illness and detecting breast cancer using breast models. One group of women collaborated with health care providers to create a baby book outlining updated knowledge and techniques for childcare during the first year of an infant's life.

The second largest number of HPTs contributed to the category of self-care for illness or injury nearly one-third of the time. Anabaptists place a high value on health and the ability to work hard (Garrett-Wright et al., 2016), and the farming environment is hazardous (Gross et al., 2015). Further, the high number of self-care topics emphasizes that accessing mainstream English medicine is usually not the first choice of this group (Schoessow, 2014). The OOMs have challenges in health care related to self-payment for health services, a preference for low technology medical treatments, and transportation to medical care (Garrett-Wright et al., 2016). When composing questions about the HPT for the speaker each month, members of the OOM community consistently conclude their questions with a request for the speaker to share strategies and techniques of how members of the community could care for themselves.

Fourteen percent of HPTs were categorized as healthy lifestyle practices. The importance of physical health in Anabaptist populations is noted in the literature (Armer \& Radina, 2002; GarrettWright et al., 2016). The OOMs are less likely to visit a provider for minor illnesses, chronic conditions, or preventive care (Schoessow, 2014). Amish adults frequently report the use of supplements and herbal remedies as complementary therapies to conventional medical treatment (Sharpnack et al., 2010). There were two HPTs on the recommended breast and colon cancer screening; however, lower rates of cancer screening have been found in the large Amish populations of Ohio (Katz et al., 2011). In addition, the community members often asked to have information on healthy lifestyle practices such as maintaining blood pressure and cholesterol at appropriate levels mailed to the community following Clinic Day.

Eight percent of HPTs were categorized as communicable diseases. Some OOM communities have increased risks for communicable disease. Well-water consumption remains common, increasing risk for exposure to pathogens in drinking water (Miller et al., 2017), and in many communities there is a lack of septic systems (Widner, 2010). Vaccinations in Old Order Mennonite adults and children also remain low (Dessecker, 2014). The community members are often interested in communicable diseases that are on the rise in the general population.

Eight percent of HPTs were categorized as navigating the health care system. OOMs pay out of pocket for their health care and negotiated self-pay health care rates between communities and heath care facilities are common. Traditionally, if costs exceed an individual's or family's ability to pay a medical bill, donations to the congregation or from the larger community are offered (Rohrer \& Dundes, 2016). Self-sufficiency and mutual aid related to health care payment contributes to community coherence and is seen as part of the sustainability of their religion over time (Ems, 2015). 
Seven percent of HPTs were categorized as mental health conditions. Mental health is an increasing priority in Anabaptist communities (Gesink et al., 2017) and members of these communities are affected by mental illness. The simplicity of lifestyle and reliance on faith may be protective for some members of the community; however, the biopsychosocial nature of disorders like anxiety and depression can be manifested in any community. The OOM community members have been open to education on both supportive counseling and medication for treatment of mental illnesses across the life span.

There are strengths and weaknesses in the design of this study. Strengths include the use of a qualitative design to use inductive reasoning to answer a question that is specific to this population. Evaluation criteria for validity in this qualitative study included credibility, dependability, and transferability. The content analysis enhanced the credibility of the findings through a prolonged immersion in three reviews of HPTs and the seeking of agreement on categorization among the four raters. Dependability was demonstrated by measures of agreement among the raters, which were substantial or nearly perfect. Transferability refers to the potential for generalization of these finding to other settings or groups. These findings are from one OOM community and may not transferable to other Old Order Anabaptist communities; however, a rich description of the community is provided. This level of detail allows the reader to discern if the findings could be transferrable to other OOM communities of interest.

\section{Conclusion}

OOM communities are diverse, and the findings from this study only reflect health practices in one Plain community. Similar studies are recommended in other OOM communities to validate or refute the findings. Collaborative research studies with cross-site comparisons could emerge as other academic practice health groups establish such partnerships with other Anabaptist communities.

A model for establishing a health promotion partnership with an OOM community is shared. The essence of the model is to maintain cultural sensitivity while using a participatory approach to provide members of the OOM community a voice in their desire and need for health information. Education in the OOM community through the HPTs has potentially aided this community with health promotion information, empowering them to make health care decisions.

\section{References}

Armer, J. M., \& Radina, M. E. (2006). Definition of health and health promotion behaviors among midwestern Old Order Amish families. Journal of Multicultural Nursing and Health, $12(3), 44-53$.

Dessecker, M. (2014). Traditional healing and medical pluralism in an Ohio Amish community [Master's thesis, Georgia State University]. ScholarWorks@ Georgia State University. https://scholarworks.gsu.edu/anthro_theses/84 
Donnermeyer, J. F., \& Anderson, C. (2014). The growth of Amish and plain Anabaptist communities in Kentucky. Journal of Amish and Plain Anabaptist Studies, 2(2), 215-44. https://doi.org/10.18061/1811/63996

Donnermeyer, J. F., \& Cooksey, E. C. (2010). On the recent growth of new Amish settlements. Mennonite Quarterly Review, 84(2), 181-207.

Elo, S., \& Kyngäs, H. (2008). The qualitative content analysis process. Journal of Advanced Nursing, 62(1), 107-15. https://doi.org/10.1111/j.1365-2648.2007.04569.x

Ems, L. (2015). Divine design: Configuring Amish communication in a high-tech world (Publication no. 3718167) [Doctoral dissertation, Indiana University]. ProQuest Dissertations \& Theses Global.

Fleiss, J. L. (1971). Measuring nominal scale agreement among many raters. Psychological Bulletin, 76(5), 378. https://doi.org/10.1037/h0031619

Garrett-Wright, D., Main, M. E., \& Jones, M. S. (2016). Anabaptist community members' perceptions and preferences related to healthcare. Journal of Amish and Plain Anabaptist Studies, 4(2), 187-200. https://doi.org/10.18061/1811/79932

Gesink, D., Leach, J., McBride, K., \& Bergin-Payette, K. (2017). Health priorities and healthseeking behaviors of Old Order Anabaptists in southern Ontario with emphasis on cancer screening. Journal of Transcultural Nursing, 28(6), 566-72.

https://doi.org/10.1177/1043659616666325

Gillum, D. R., Staffileno, B. A., Schwartz, K. S., Coke, L., Fogg, L., \& Reiling, D. (2011). Cardiovascular disease in the Amish: An exploratory study of knowledge, beliefs, and health care practices. Holistic Nursing Practice, 25(6), 289-97. https://doi.org/10.1097/HNP.0b013e318232c58d

Gross, N., Young, T., Ramirez, M., Leinenkugel, K., \& Peek-Asa, C. (2015). Characteristics of work- and non-work-related farm injuries. Journal of Rural Health, 31(4), 401-9. https://doi.org/10.1111/jrh.12121

Hunt, M., Jones, M., Main, M., Carter, D., Cary, K., \& Hall, M. (2019). Genetic medical clinic in Kentucky: A needs assessment of Anabaptist households. Journal of Amish and Plain Anabaptist Studies, 6(2), 159-73. https://doi.org/10.18061/1811/87097

Israel, B. A., Schulz, A. J., Parker, E. A., \& Becker, A. B. (2001). Community-based participatory research: Policy recommendations for promoting a partnership approach in health research. Education for Health, 14(2), 182-97.

Jones, M. S., Main, M. E., \& Garrett, D. M. (2013). A collaborative educational innovation in an Old Order Mennonite community. Journal of the National AHEC Organization, 29(1), 2427.

Katz, M. L., Ferketich, A. K., Paskett, E. D., \& Bloomfield, C. D. (2013). Health literacy among the Amish: Measuring a complex concept among a unique population. Journal of Community Health, 38(4), 753-58. https://doi.org/10.1007/s10900-013-9675-z 
Katz, M. L., Ferketich, A. K., Paskett, E. D., Harley, A., Reiter, P. L., Lemeshow, S., Westman, J. A. Clinton, S. K., \& Bloomfield, C. D. (2011). Cancer screening practices among Amish and non-Amish adults living in Ohio Appalachia. Journal of Rural Health, 27(3), 302-9. https://doi.org/10.1111/j.1748-0361.2010.00345.x

Kraybill, D. B., \& Hurd, J. P. (2006). Horse-and-buggy Mennonites: Hoofbeats of humility in a postmodern world. Pennsylvania State University Press.

Landis, J. R., \& Koch, G. G. (1977). The measurement of observer agreement for categorical data. Biometrics, 33(1), 159-74. https://doi.org/10.2307/2529310

Miller, K., Yost, B., Abbott, C., Thompson, S., Dlugi, E., Adams, Z., Schulman, M., \& Strauss, N. (2017). Health needs assessment of plain populations in Lancaster County, Pennsylvania. Journal of Community Health, 42(1), 35-42. https://doi.org/10.1007/s10900-016-0223-5

Perinetti, G. (2017). StaTips Part III: Assessment of the repeatability and rater agreement for nominal and ordinal data. South European Journal of Orthodontics and Dentofacial Research, 4(1), 3-4. https://doi.org/10.5937/sejodr4-1283

Rohrer, K., \& Dundes, L. (2016). Sharing the load: Amish healthcare financing. Healthcare 4(4), 92. https://doi.org/10.3390/healthcare4040092

Schoessow, C. J. (2014). An assessment of Old Order Amish general health beliefs, practices and health-seeking behaviors in Clark County, Wisconsin. [Doctoral dissertation, Medical University of South Carolina]. ProQuest Dissertations \& Theses Global.

Scott, S. E. (1996). An Introduction to Old Order and Conservative Mennonite Groups. Good Books.

Sharpnack, P. A., Griffin, M. T. Q., Benders, A. M., \& Fitzpatrick, J. J. (2010). Spiritual and alternative healthcare practices of the Amish. Holistic Nursing Practice, 24(2), 64-72. https://doi.org/10.1097/HNP.0b013e3181d39ade

Viera, A. J., \& Garrett, J. M. (2005). Understanding interobserver agreement: The kappa statistic. Family Medicine, 37(5), 360-63.

Widner, D. E. (2010). Old Order Amish beliefs about environmental protection and the use of best management practices in the Sugar Creek Watershed (Master's thesis, Kent State University).

Young Center for Anabaptist and Pietist Studies. (2020). Amish population, 2020. Amish Studies. https://groups.etown.edu/amishstudies/statistics/statistics-population-2020/ 